\title{
Characterising the role of the Eucalyptus grandis SND2 promoter in secondary cell wall biosynthesis
}

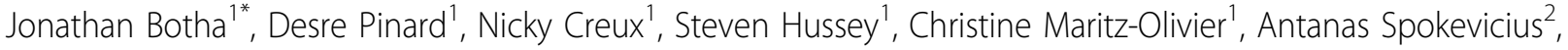 \\ Gerd Bossinger ${ }^{2}$, Eshchar Mizrachi ${ }^{1}$, Alexander Myburg ${ }^{1}$
}

From IUFRO Tree Biotechnology Conference 2011: From Genomes to Integration and Delivery Arraial d Ajuda, Bahia, Brazil. 26 June - 2 July 2011

\section{Background}

NAC and MYB transcription factors (TFs) have been shown to play prominent roles in the regulation of plant developmental processes. Two Arabidopsis thaliana NAC domain TFs (AtSND2, AtSND3) and one MYB domain TF (AtMYB103) were shown to be downstream targets of two master regulators of xylem fibre cell development, NST1 and SND1 $[1,2]$. These TFs were able to induce the expression of a GUS reporter gene under the control of the AtCesA8 promoter [3], indicating that they may be involved in the regulation of cellulose biosynthesis in the secondary cell walls of $A$. thaliana xylem fibres. It is hypothesized that putative orthologs of these TFs will also play important roles in regulating fibre secondary cell wall biosynthesis in woody plants such as Eucalyptus grandis. The transcriptional network regulating wood fibre development is uncharacterized in E. grandis, therefore it would be beneficial to identify upstream components of this transcriptional network in E. grandis. In this ongoing study we aim to identify TFs which bind to the promoter of the putative ortholog of AtSND2 in E. grandis (EgSND2) and possibly also to the promoters of the orthologs of AtSND3 and AtMYB103. In parallel, we are characterizing the detailed heterologous expression patterns of the EgSND2, EgSND3 and MYB103 promoter regions in A. thaliana plants. This work forms part of an effort to elucidate the transcriptional network regulating wood fibre development in E. grandis.

\footnotetext{
* Correspondence: Jonathan.Botha@fabi.up.ac.za

${ }^{1} 1$ Department of Genetics, Forestry and Agricultural Biotechnology Institute (FABI), University of Pretoria, Pretoria, 0002, South Africa

Full list of author information is available at the end of the article
}

\section{Methods}

A reverse BLAST approach was used to identify candidate orthologs of AtSND2, AtSND3 and AtMYB103 in Eucalyptus, Populus and Vitis. In silico cis-element analysis was performed on the promoter regions of the putative orthologs to identify previously characterised and novel cis-elements. The $1.5 \mathrm{~kb}$ regions upstream of the translational start site (TSS) of EgSND2, EgSND3 and $E g M Y B 103$ were isolated from E. grandis genomic DNA. The amplified fragments were cloned into pMDC162, a GUS reporter vector, and introduced into A. thaliana Col-O plants for heterologous GUS expression analysis. The same reporter constructs were also transformed directly into the vascular cambium of potted E. grandis plants to determine endogenous promoter activity by Induced Somatic Sector Analysis (ISSA, [4]). Qualitative GUS reporter analyses were performed on the EgSND2promoter::GUS, EgSND3promoter::GUS and EgMYB103promoter::GUS constructs in Arabidopsis plants at 1, 3 and 6 weeks. A 500 bp truncation upstream of the TSS of EgSND2 was generated and cloned into the pHIS2.1 vector along with the $1.5 \mathrm{~kb}$ EgSND2 promoter sequence for use in yeast onehybrid (Y1-H) screening. Candidate proteins which bind to the cloned promoter sequences will be identified using $\mathrm{Y} 1-\mathrm{H}$ analysis and further characterised.

\section{Results and discussion}

A number of previously described (e.g. [5]) and novel cis-elements were present in the three cloned Eucalyptus promoters (EgSND2, EgSND3 and EgMYB103)suggesting regulation by an overlapping set of upstream transcription factors. The 1, 3 and 6-week GUS analyses of the EgSND2promoter::GUS and EgSND3promoter::GUS 
constructs revealed strong GUS expression in vascular tissues, but the GUS expression was not specific to vascular tissues as reported for the endogenous AtSND2 and AtSND3 genes [3]. This suggests that the $1.5 \mathrm{~kb}$ region upstream of the translational start site may not be sufficient for fibre-specific expression in a heterologous system. Similarly, the EgMYB103promoter::GUS construct was expressed in stems and leaves, in contrast to strong stem specificity reported by Zhong et al., [3] for the Arabidopsis ortholog. ISSA (ongoing) results of endogenous expression in Eucalyptus may clarify the possible regulatory divergence in these promoter sequences. We hope to soon identify and functionally annotate a number of protein candidates binding to the EgSND2 promoter using $\mathrm{Y} 1-\mathrm{H}$ analysis.

\section{Conclusions}

The EgSND2, EgSND3 and EgMYB103 promoters were found to contain common cis-regulatory elements, which suggests at least partial co-regulation in $E$. grandis. The $1.5 \mathrm{~kb}$ upstream regions of EgSND2, EgSND3 and EgMYB103 induced strong heterologous GUS expression in vascular and non-vascular tissues of A. thaliana suggesting either that these promoter sequences have functionally diverged in Arabidopsis and Eucalyptus, or that the $1.5 \mathrm{~kb}$ upstream regions alone are not sufficient to induce fibre-specific expression as previously reported in Arabidopsis.

\section{Author details}

${ }^{1} 1$ Department of Genetics, Forestry and Agricultural Biotechnology Institute (FABI), University of Pretoria, Pretoria, 0002, South Africa. ${ }^{2} 2$ Department of Forest and Ecosystem Science, Melbourne School of Forest and Ecosystem Science, University of Melbourne, Australia.

Published: 13 September 2011

\section{References}

1. Mitsuda N, Iwase A, Yamamoto H, Yoshida M, Seki M, Shinozaki K, OhmeTakagi M: NAC transcription factors, NST1 and NST3, are key regulators of the formation of secondary walls in woody tissues of Arabidopsis. Plant Cell 2007, 19:270-280.

2. Zhong R, Demura T, Ye ZH: SND1, a NAC domain transcription factor, is a key regulator of secondary wall synthesis in fibers of Arabidopsis. Plant Cell 2006, 18:3158-3170.

3. Zhong R, Lee C, Zhou J, McCarthy RL, Ye ZH: A battery of transcription factors involved in the regulation of secondary cell wall biosynthesis in Arabidopsis. Plant Cell 2008, 20:2763-2782.

4. Van Beveren KS, Spokevicius AV, Tibbits J, Wang Q, Bossinger G: Transformation of cambial tissue in vivo provides an efficient means for induced somatic sector analysis and gene testing in stems of woody plant species. Functional Plant Biology 2006, 33:629-638.

5. Creux NM, Ranik M, Berger DK, Myburg AA: Comparative analysis of orthologous cellulose synthase promoters from Arabidopsis, Populus and Eucalyptus: evidence of conserved regulatory elements in angiosperms. New Phytol 2008, 179:722-737.

\section{doi:10.1186/1753-6561-5-S7-P105}

Cite this article as: Botha et al:: Characterising the role of the Eucalyptus grandis SND2 promoter in secondary cell wall biosynthesis. BMC

Proceedings 2011 5(Suppl 7):P105.

\section{Submit your next manuscript to BioMed Central and take full advantage of:}

- Convenient online submission

- Thorough peer review

- No space constraints or color figure charges

- Immediate publication on acceptance

- Inclusion in PubMed, CAS, Scopus and Google Scholar

- Research which is freely available for redistribution 